\title{
A post-Paris look at climate observations
}

To the Editor - The Paris Agreement ${ }^{1}$ of the United Nations Framework Convention on Climate Change in December 2015 was a landmark event. Stakeholders such as cities, companies and citizens that endure the impacts of a changing climate, as well as policymakers, now need to know what impact their future choices will have on the environment. Systematic observations of the climate system and of greenhouse gas (GHG) emissions are needed to track progress and identify where additional goals may be needed. We suggest that, although the targets agreed in Paris - to hold global warming to well below $2{ }^{\circ} \mathrm{C}$ and avert loss and damage - are formulated around temperature, monitoring and meeting these targets requires a broader range of climate indicators ${ }^{2}$. Global mean surface temperature alone has proved problematic for communicating the impacts and evolution of climate change. The warming of the oceans, sea-level rise, increasing ocean acidity, melting glaciers and decreasing snow cover, and changes in Arctic sea ice also need to be taken into account.

Such a set of indicators should be able to convey the range of climate change impacts and how they are evolving. Following the Paris Agreement, policymakers will need reliable evidence of the impacts of climate change on society to assess the increasing risks, for example to infrastructure, food security and water resources.

Through the Global Climate Observing System (GCOS), a set of 51 essential climate variables (ECVs) have been defined: they aim to describe key aspects of the behaviour and composition of the land, oceans and atmosphere (see Table 1). This in turn has led to substantial investment, and to improvements in the implementation of a space-based and in situ monitoring system for the climate research community ${ }^{3,4}$. This collective effort provides remarkable understanding of the climate.

The concept of defining ECVs has proved very effective. It has now been adopted by a number of other scientific communities, particularly linked to multilateral environmental agreements such as the UN Convention on Biological Diversity and the UN Sustainable Development Goals. Examples include - in various stages of implementation - essential ocean variables $^{5}$, essential biodiversity variables ${ }^{6}$ and essential water variables ${ }^{7}$. Observing these essential variables will yield sustained global information on changes in key Earth system variables, and hence a better scientific understanding of future risks. This knowledge can feed into the development of specific prevention, adaptation and mitigation efforts. GCOS is now expanding its framework of ECVs to include those required to close the cycles of energy, water and carbon.

We need continuous and systematic climate observations of a wellthought-out set of indicators to monitor the targets of the Paris Agreement, and the data must be made available to all interested users. The Paris Agreement serves as a strong reminder to the observing community to deliver the data that will underpin progress.

References

1. Adoption of the Paris Agreement FCCC/CP/2015/10/Add.1 (UNFCCC, 2015).

2. Briggs, S., Kennel, C. F. \& Victor, D. G. Nat. Clim. Change 5, 969-970 (2015).

3. Bojinski, S. et al. Bull. Am. Meteorol. Soc. 95, 1431-1443 (2014).

4. Implementation Plan for the Global Observing System for Climate in Support of the UNFCCC (2010 update) GCOS-138, WOM (Global Climate Observing System, 2010); http://go.nature. com/2bj1JzT

5. Essential Ocean Variables (Ocean Observations Panel for Climate, 2016); http://ioc-goos-oopc.org/obs/ecv.php

6. More Data $\neq$ Better Monitoring (GEO BON, 2015); http://go.nature.com/2b0Y5HN

7. The GEOSS Water Strategy: From Observations to Decisions (GEO Group on Earth Observations, 2013); http://go.nature. com/2aYEqpM

8. The Global Observing System for Climate: Implementation Needs GCOS-195 (World Meteorological Organization, 2016); http://go.nature.com/2b6mAol

A. Johannes Dolman ${ }^{1 *}$, Alan Belward², Stephen Briggs ${ }^{3}$, Mark Dowell ${ }^{2}$, Simon Eggleston ${ }^{3}$, Katherine Hill ${ }^{3}$, Carolin Richter ${ }^{3}$ and Adrian Simmons ${ }^{4}$ ${ }^{1}$ Department of Earth Sciences, Free University Amsterdam, 1081 HV Amsterdam, the Netherlands. ${ }^{2}$ European Commission, DG Joint Research Centre, Institute for Environment and Sustainability, H05 Land Resource Management, Via Fermi, 21027 Ispra, Italy. ${ }^{3}$ Global Climate Observing System (GCOS), World Meteorological Organization (WMO) 7 bis, Avenue de la Paix, CH-1211 Geneva 2, Switzerland. ${ }^{4}$ European Centre for Medium-Range Weather Forecasts, Reading RG2 9AX, UK. *e-mail: han.dolman@vu.nl

Table 1 | List of essential climate variables as proposed the in the draft GCOS Implementation Plan (ref. 8).

$\begin{array}{ll}\begin{array}{l}\text { Energy and } \\ \text { temperature }\end{array} & \begin{array}{l}\text { Atmosphere } \\ \text { budget, surface temperature, upper air } \\ \text { temperature. }\end{array} \\ \begin{array}{l}\text { Other physical } \\ \text { properties }\end{array} & \begin{array}{l}\text { Surface wind, upper air wind, cloud properties, } \\ \text { pressure, lightning, aerosol properties. }\end{array} \\ \begin{array}{l}\text { Carbon cycle } \\ \text { and other GHGs } \\ \text { Hydrosphere }\end{array} & \begin{array}{l}\mathrm{CO}_{2} \text {, methane, other long-lived GHGs, ozone, } \\ \text { precursors for aerosol and ozone. }\end{array} \\ & \begin{array}{l}\text { Precipitation, water vapour (surface) } \\ \text { water vapour (upper air). }\end{array}\end{array}$

Snow and ice

Biosphere

Human resource use

\section{Terrestrial}

Albedo, latent and sensible heat fluxes,

land surface temperature.

Ocean

Ocean surface heat flux, sea surface temperature, temperature (sub-surface).

Currents, surface currents, ocean surface stress, sea surface salinity, salinity, sea state, transient tracers.

Soil carbon, above-ground biomass.

Soil moisture, river discharge, lakes, groundwater.

Glaciers, ice sheets and ice shelves, permafrost, snow.

Land cover, leaf area index ( $L A I)$, fraction of absorbed photosynthetically active radiation (FAPAR), fire.

Wateruse, GHG fluxes.
Inorganic carbon, $\mathrm{N}_{2} \mathrm{O}$.

Sea level.

Sea ice.

Plankton, $\mathrm{O}_{2}$, nutrients, ocean colour, marine habitat properties. 